\title{
A hybrid nanofiber matrix to control the survival and maturation of brain neurons
}

\author{
Shantanu Sur ${ }^{\mathrm{a}, \mathrm{e}, \mathrm{g}}$, Eugene T. Pashuck ${ }^{\mathrm{c}}$, Mustafa O. Guler ${ }^{\mathrm{c}, \mathrm{f}}$, Masao Ito ${ }^{\mathrm{a}}$, Samuel I. Stupp ${ }^{\mathrm{c}, \mathrm{d}, \mathrm{e}}$, \\ Thomas Launey ${ }^{\mathrm{a}, \mathrm{b}, *}$
}

a Laboratory for Memory and Learning, RIKEN Brain Science Institute, Wako-shi, 351-0198 Saitama, Japan

${ }^{\mathrm{b}}$ Launey Research Unit for Molecular Neurocybernetics, RIKEN Brain Science Institute, Wako-shi, 351-0198 Saitama, Japan

${ }^{c}$ Department of Materials Science and Engineering, Northwestern University, 2220 Campus Dr., Evanston, IL 60208, USA

d Department of Chemistry, Northwestern University, 2220 Campus Dr., Evanston, IL 60208, USA

e Institute for Bionanotechnology in Medicine (IBNAM), Northwestern University, Chicago, IL 60611, USA

${ }^{\mathrm{f}}$ UNAM-Institute of Materials Science and Nanotechnology, Bilkent University, Turkey

${ }^{\mathrm{g}}$ School of Medical Science and Technology, IIT Kharagpur 721302, India

\section{A R T I C L E I N F O}

Article history:

Received 7 September 2011

Accepted 29 September 2011

Available online 20 October 2011

\section{Keywords:}

Self assembly

Laminin

Collagen

Peptide amphiphile

Nerve tissue engineering

Brain

\begin{abstract}
A B S T R A C $T$
Scaffold design plays a crucial role in developing graft-based regenerative strategies, especially when intended to be used in a highly ordered nerve tissue. Here we describe a hybrid matrix approach, which combines the structural properties of collagen (type I) with the epitope-presenting ability of peptide amphiphile (PA) nanofibers. Self-assembly of PA and collagen molecules results in a nanofibrous scaffold with homogeneous fiber diameter of $20-30 \mathrm{~nm}$, where the number of laminin epitopes IKVAV and YIGSR can be varied by changing the PA concentrations over a broad range of $0.125-2 \mathrm{mg} / \mathrm{ml}$. Granule cells (GC) and Purkinje cells (PC), two major neuronal subtypes of cerebellar cortex, demonstrate distinct response to this change of epitope concentration. On IKVAV hybrid constructs, GC density increases three-fold compared with the control collagen substrate at a PA concentration of $\geq 0.25 \mathrm{mg} / \mathrm{ml}$, while PC density reaches a maximum (five-fold vs. control) at $0.25 \mathrm{mg} / \mathrm{ml}$ of PA and rapidly decreases at higher PA concentrations. In addition, adjustment of the epitope number allowed us to achieve fine control over PC dendrite and axon growth. Due to the ability to modulate neuron survival and maturation by easy manipulation of epitope density, our design offers a versatile test bed to study the extracellular matrix (ECM) contribution in neuron development and the design of optimal neuronal scaffold biomaterials.
\end{abstract}

(C) 2011 Elsevier Ltd. All rights reserved.

\section{Introduction}

The function of the central nervous system is determined by a precisely connected network among neurons. Symptoms of neurological deficits following injury or disease result from the disruption of this network, and one of the main goals of neural tissue engineering is to rebuild the damaged neurons into functional tissue [1]. Neural stem cell based techniques present one particularly promising approach [2], and delivering them using a supporting scaffold offers distinct advantage in terms of cell survival, retention and differentiation [3-5]. Apart from being a structural support, ideally the scaffold should provide essential

Abbreviations: PA, peptide amphiphile; PC, purkinje cell; GC, granule cell; DIV, days in vitro; ECM, extracellular matrix.

* Corresponding author. Launey Research Unit for Molecular Neurocybernetics, RIKEN Brain Science Institute, Wako-shi, 351-0198 Saitama, Japan. Tel.: +8148462 1613; fax: +8148462 4697 .

E-mail address: t_launey@brain.riken.jp (T. Launey). biophysical and biochemical instructive cues for the desired cell response [6]. The novel design strategies afforded by the recent advancements in nanoscale technologies seem likely to play a central role to achieve this goal [7-9].

Since the natural ECM molecules within the cellular microenvironment guide cell development and maturation [10], one general strategy to improve scaffold bioactivity involves incorporation of specific ECM-derived signals. Identification of cell adhesion short peptide sequences present in the ECM proteins [11] has led to the development of a large number of biomimetic materials for neural and other tissues [12]. For the nervous system in particular, the ECM protein laminin has been shown to play a critical role in multiple stages of development [13]; a number of laminin-derived short bioactive sequences such as IKVAV, YIGSR and RNIAEIIKDI have been reported to promote cell attachment, neurite outgrowth and axon guidance [14-17]. Matrix scaffolds modified by these epitopes, show significant improvement in terms of neuronal differentiation, attachment and neurite growth, and can also be engineered to guide axonal extensions $[3,18,19]$. In vivo, 
IKVAV and YIGSR peptide presenting scaffolds have been shown to promote spinal cord and peripheral nerve regeneration respectively [20,21]. Their efficacy, however, often depends on the density of the presented epitopes, as suggested by in vitro studies; for example, in a laminin epitope modified fibrin gel, neurite growth responses of dorsal root ganglion neurons were dependent on the epitope concentration [18].

Peptide amphiphile (PA) nanofiber scaffolds are designed to present cells with bioactive epitopes at a very high density, and provide a common platform for a wide variety of regenerative medicine applications including angiogenesis, cartilage, bone and neuronal regeneration [20,22-26]. Self-assembly of PA molecules into nanofiber networks from solution is triggered by charge screening when $\mathrm{pH}$ or salt concentration is changed. Screening commonly results in the formation of networks containing bundled or entangled fibers with individual diameters in the order of $6-10 \mathrm{~nm}[3,8]$. Fiber assembly is favored by a $\beta$-sheet forming amino acid sequence placed near the hydrophobic tail of these molecules, while the peptide segment near the fiber surface is designed to display specific bioactive sequences [9,27]. Such molecular design has been shown to be successful in presenting ECM-derived signals or to enhance the availability of endogenous growth factors in the scaffold [24,28]. IKVAV epitope-presenting PA scaffolds have been previously shown to selectively promote neuronal differentiation from neuroprogenitor cells in vitro [3]. Furthermore, injecting this scaffold in rodent spinal cord injury models resulted in axonal regeneration through the lesion, along with an enhanced serotoninergic fiber density caudal to the lesion, leading to improved functional recovery $[20,29]$.

We describe here the design of a hybrid matrix that combines neuro-active PAs with collagen. The underlying motivation for the combinatorial approach is to control matrix bioactivity by adjusting the laminin epitope concentration using PAs, while maintaining the favorable mechanical properties of collagen (which alone can form stable gels and is widely used for 3D cell culture studies [30,31]). The role of hybrid matrix in supporting the development of central nervous system neurons was evaluated here using rat cerebellar neurons. The number of cerebellar granule cell (GC) and Purkinje cell (PC) are tightly regulated during development $[32,33]$ and they acquire very characteristic dendrite morphologies upon maturation, resulting in the highly stereotyped neuronal circuit of the cerebellar cortex [34]. These well characterized features provide a bioactivity index to evaluate the hybrid matrix in vitro.

\section{Materials and methods}

\subsection{Preparation of hybrid matrix}

Branched PA molecules were obtained by solid-phase peptide synthesis (SPPS) as previously described [35]. Fmoc-protected amino acids, MBHA rink amide resin, and HBTU were purchased from NovaBiochem (USA) and all other reagents were purchased from Fisher (USA) or Sigma-Aldrich (USA). PA stock solutions ( $1 \% \mathrm{w} / \mathrm{v}$; $\mathrm{pH} 4$ ) in water were homogenized by sonication in a water bath for 20 min prior to their use. Collagen (Type1) was extracted from the tail tendon of 3-4 month old Wistar rats, following the method outlined in [36], with some modifications. In brief, the collected tendons from the rat-tail were dissolved by stirring in $0.1 \mathrm{~m}$ acetic acid and purified by centrifugation and repeated dialysis. The purified sample was finally dialyzed against 0.1X DMEM solution (adjusted to $\mathrm{pH} 4.0$ with $\mathrm{HCl}$ ), and stored at $-80{ }^{\circ} \mathrm{C}$. The purity of the collagen was confirmed by $5 \%$ SDS-PAGE electrophoresis and concentration was measured using an EZQ protein quantification kit (Molecular Probes, Inc.). In all gels prepared for neuronal culture, the final collagen concentration was $1.8 \mathrm{mg} / \mathrm{ml}$. Collagen and PA stock solutions were diluted to appropriate working concentration in sterile milliQ water at $4{ }^{\circ} \mathrm{C}$. The solutions (total volume $50 \mu \mathrm{l})$ were mixed quickly in the center well ( $8 \mathrm{~mm}$ diameter) of glass bottomed $35 \mathrm{~mm}$ Petri dish (Falcon 3001). The collagen-PA mixture was exposed to ammonia vapor for $10 \mathrm{~min}$ at room temperature (RT) to induce gel formation. To ensure complete supramolecular polymerization and to exchange buffer, $100 \mu$ l DMEM solution was added on top of the gel and left overnight in an incubator at $37^{\circ} \mathrm{C}$ and $5 \% \mathrm{CO}_{2}$, prior to cell experiments.

\subsection{Rheology}

Rheological measurements were performed using a Paar Physica rheometer (MCR 300), operating in $25 \mathrm{~mm}$ parallel plate configuration. The stage temperature was maintained at $5{ }^{\circ} \mathrm{C}$ (Except during the gelation studies using ammonia vapor, when the temperature was raised to $25^{\circ} \mathrm{C}$ ), and the gap between the plates was fixed at $0.5 \mathrm{~mm}$ (requiring $300 \mu \mathrm{l}$ sample volume). Samples were tested at $0.5 \%$ oscillatory strain over angular frequency range of $1-100 \mathrm{~s}^{-1}$, after an initial equilibration period of $30 \mathrm{~min}$. Ammonia-induced gel transformation of the sample solutions was carried out by a $10 \mathrm{~min}$ exposure to ammonia vapor on the stage.

\subsection{Circular dichroism (CD) spectroscopy}

CD spectra were obtained from $250 \mathrm{~nm}$ to $185 \mathrm{~nm}$ using a Jasco J-715 spectrometer. For the measurements, collagen and PA stock solutions were diluted in milliQ water to final concentration of $2.7 \times 10^{-3} \mathrm{mg} / \mathrm{ml}$ and $3.0 \times 10^{-3} \mathrm{mg} / \mathrm{ml}$ respectively.

\subsection{Thioflavin $T(T h T)$ fluorescence assay}

A stock solution of $0.5 \%$ ThT (Sigma) was freshly prepared in $5 \mathrm{~mm}$ pyruvic acid buffer ( $\mathrm{pH} 4$ ) and filtered through $0.22 \mu \mathrm{m}$ cellulose acetate filter. The final concentration of ThT ( $50 \mu \mathrm{m})$ was obtained by diluting $1 \mu \mathrm{l}$ of the stock solution to $300 \mu \mathrm{l}$. An emission spectrum was obtained with a Jasco FP-750 spectrofluorometer using quartz cuvette of $3 \mathrm{~mm}$ optical path length. The sample was excited $\left(\lambda_{\text {ex }}\right)$ at $440 \mathrm{~nm}$ and the emission spectrum was acquired in the wavelength range of $450-600 \mathrm{~nm}$. Measurements were made for the collagen $(1.8 \mathrm{mg} / \mathrm{ml})$ solution, PA ( $2 \mathrm{mg} / \mathrm{ml}$ ) solution and their combination in pyruvic acid buffer ( $\mathrm{pH} 4)$. The measurement of the PA emission was repeated at $\mathrm{pH} 7$ by changing the buffer to phosphate buffered saline (PBS).

\subsection{Atomic force microscopy (AFM)}

AFM imaging was performed on a Bioscope II (Veeco) operating in tapping mode in air. Stock solutions of the PA $(10 \mathrm{mg} / \mathrm{ml})$, collagen $(2.2 \mathrm{mg} / \mathrm{ml})$ or their combination (collagen $1.8 \mathrm{mg} / \mathrm{ml}$, PA $2 \mathrm{mg} / \mathrm{ml}$ ) were diluted 50-100 fold with milliQ water and $80 \mu \mathrm{l}$ of the diluted solution was adsorbed on a freshly cleaved mica surface for $2 \mathrm{~min}$. The surface was dried using a stream of air and height images were acquired by using a silicon cantilever (Applied NanoStructures, USA) with a nominal force constant of $40 \mathrm{~N} / \mathrm{m}$ and resonant frequency of $300 \mathrm{kHz}$.

\subsection{Transmission electron microscopy (TEM)}

A small volume $(5-10 \mu \mathrm{L})$ of the sample $(\mathrm{PA} 1 \mathrm{mg} / \mathrm{ml}$; collagen $0.22 \mathrm{mg} / \mathrm{ml}$ collagen $0.18 \mathrm{mg} / \mathrm{ml}+\mathrm{PA} 0.2 \mathrm{mg} / \mathrm{ml}$ ) was applied to a copper TEM grid with a carbon support film (Electron Microscopy Sciences, USA). Excess solution was wicked away with filter paper, and once dried the samples were negatively stained using a $2 \%(\mathrm{w})$ v) uranyl acetate (Electron Microscopy Sciences) solution in water. Images of negatively stained samples were obtained on a Tecnai Spirit G2 microscope (FEI) operating at $120 \mathrm{kV}$.

\subsection{Cryogenic transmission electron microscopy (cryo-TEM)}

Cryo-TEM was performed on a JEOL 1230 microscope operating at $100 \mathrm{kV}$. Stock solutions of the PA $(10 \mathrm{mg} / \mathrm{ml})$, collagen $(2.2 \mathrm{mg} / \mathrm{ml})$ or their combination (collagen $1.8 \mathrm{mg} / \mathrm{ml}$, PA $2 \mathrm{mg} / \mathrm{ml}$ ) were diluted 2-5 times in milliQ water, and a small volume of the sample $(5-10 \mu \mathrm{L})$ was applied to a copper TEM grid with holey carbon support film (Electron Microscopy Sciences). The sample specimen was blotted under a controlled environment and vitrified using a Vitrobot Mark IV (FEI) device. The vitrified samples were introduced in the scope by a Gatan 626 cryo-holder, and imaged using a Hamamatsu ORCA CCD camera.

\subsection{Confocal reflection microscopy (CRM)}

CRM of gel samples was performed on LSM 510 META (Zeiss) inverted laser scanning confocal microscope. Gel samples were prepared in the center well of glass-bottom $35 \mathrm{~mm}$ Petri dishes (following the procedure used for cell experiments), and kept hydrated by the addition of phosphate buffered saline. A $488 \mathrm{~nm}$ laser source was used to image the gel samples.

\subsection{Scanning electron microscopy (SEM)}

SEM samples were processed as previously described [37]. After dehydration through graded ethanol concentrations, the specimens were transferred to $t$-butyl alcohol for three rinses, then frozen and freeze-dried (VFD-21S, Vacuum Device Co. Ltd., Mito, Japan), sputter-coated with osmium (VE3030CVD, Vacuum Device) and imaged using a field emission SEM (LEO 1530, LEO, Oberkochen, Germany). 


\subsection{Cerebellar neuronal culture}

Cerebellar cultures were prepared from Wistar rat fetuses (embryonic day 18) using an established protocol $[38,39]$ with some modifications. Briefly, embryos collected from anaesthetized pregnant rats were dissected in cold $\mathrm{Ca}^{++} / \mathrm{Mg}^{++}$-free Hank's BSS. Washed cerebella were sequentially digested in $0.25 \%$ bovine pancreas trypsin for $20 \mathrm{~min}$ at room temperature and with $0.05 \%$ DNase in $12 \mathrm{~mm} \mathrm{MgSO}_{4}$ at $4{ }^{\circ} \mathrm{C}$, followed by mechanical trituration with a fire-polished Pasteur pipette. After complete dissociation of the tissue, the cell suspension was placed on top of $10 \%$ and $60 \%$ Percoll solutions in a $15 \mathrm{ml}$ tube and centrifuged at $3000 \mathrm{~g}$ for $15 \mathrm{~min}$. Cells were collected from the $10-60 \%$ interface and diluted in seeding medium containing DMEM F-12 and 10\% inactivated horse serum. This suspension was seeded on preformed gel or on poly-lysine poly-ornithine coated coverslips, at concentration of 4800 cells $/ \mathrm{mm}^{2}$ and 4300 cells $/ \mathrm{mm}^{2}$ respectively, and cultured in $1 \mathrm{ml}$ of culture medium with composition as in [38] with addition of $1.5 \%$ inactivated horse serum and $25 \%$ astrocyte-conditioned medium (Sumitomo Bakelite, Japan). Half of the medium was replaced on the 14th day and every 7th day thereafter. All saline solutions were obtained from Gibco BRL Life Tech (Tokyo, Japan), while reagents and enzymes were obtained from Sigma (Tokyo, Japan). Dissection and animal handling were carried out in accordance with the National Institutes of Health Guide for the Care and Use of Laboratory Animals, and specifically approved by the Research Ethics Section Safety Center of the RIKEN Institute.

\subsection{Immunostaining}

Cultured cells were fixed with $4 \%$ paraformaldehyde in $0.1 \mathrm{M}$ PBS $(\mathrm{pH} 7.4$, $340 \mathrm{mOsm}$ ) at $4{ }^{\circ} \mathrm{C}$, then blocked with $10 \%$ normal goat serum, $2 \%$ BSA in PBS and $0.4 \%$ Triton X-100. The following primary antibodies (with indicated dilutions) were used for immuno-detection: Mouse anti-neuronal nuclei (NeuN) monoclonal (1:500, Chemicon International, USA); mouse anti-tubulin, beta III isoform monoclonal (1:1000, Chemicon); anti-Calbindin D-28K (mouse monoclonal, 1:1000, Swant, Bellinzona, Switzerland and rabbit polyclonal, 1:1000, Chemicon); antimicrotubule-associated-protein 2 (MAP2) polyclonal (rabbit 1:2000, Chemicon and chicken 1:10,000, Novus Biologicals, Littleton, USA); mouse anti-synaptophysin monoclonal $(1: 10,000$, Chemicon). The primary antibodies were incubated overnight at $4{ }^{\circ} \mathrm{C}$ then detected with the appropriate dye-conjugated secondary antibodies (Molecular Probes, Inc., $2 \mathrm{hr}$ incubation at RT).

\subsection{Image acquisition and analysis}

Neuronal attachment to the gel surface was assessed by phase contrast images (NIKON Diaphot 300). Fluorescently stained samples were imaged either using a cooled CCD camera (Coolsnap Photometrics, Tucson, AZ) attached to an upright microscope (BX51, Olympus) or with a confocal laser scanning microscope (FV500, Olympus). Deconvolution of confocal image stacks was performed using the Huygens software (Scientific Volume Imaging, Netherlands). PC surface dendrite growth was quantified by estimating PC projected surface area and 2D convex hull from the upper $20 \mu \mathrm{m}$ of the confocal stacks, in order to exclude the penetrating branches from the estimation. The area covered by a single PC soma and its dendrites following maximum intensity projection along the $Z$-axis was considered as the projected surface area. The convex hull, an index of PC dendritic spread on the substrate, was defined as the total area obtained by joining the most distal dendritic tips with straight lines. Analyses were performed semi-automatically using routines written in Matlab and Image ( $\mathrm{NIH}$ ) software. Neuron density estimates were obtained from NeuN stained culture using the nuclei counting module in Image software.

\subsection{Electrophysiological recording}

Whole-cell voltage-clamp and current clamp recordings were performed on the PCs cultured on the collagen-PA gel, under phase-contrast observation. An inverted microscope (NIKON TE2000), with long working distance, phase contrast objectives was used to enable focusing through the $\sim 350 \mu \mathrm{m}$ thick gel. The extracellular solution contained $140 \mathrm{~mm} \mathrm{NaCl}, 3 \mathrm{~mm} \mathrm{KCl}, 3 \mathrm{~mm} \mathrm{CaCl}_{2}, 1 \mathrm{~mm} \mathrm{MgSO}_{4}, 0.5 \mathrm{~mm}$ $\mathrm{Na}_{2} \mathrm{HPO}_{4}, 10 \mathrm{~mm}$ D-glucose, 10 mм HEPES, 3 mм Na-pyruvate ( $\mathrm{pH} 7.35,330 \pm 5$ mOsm, $33^{\circ} \mathrm{C}$ ). The pipette-filling solution contained $60 \mathrm{~mm}$ K-gluconate, $60 \mathrm{~mm}$ K-methanesulfonate, $20 \mathrm{~mm} \mathrm{KCl,} 3 \mathrm{~mm} \mathrm{MgCl}$, 4 mм Na 2 ATP, $0.4 \mathrm{~mm}$ NaGTP, $15 \mathrm{~mm}$ HEPES, $2 \mathrm{~mm}$ EGTA, $0.8 \mathrm{~mm} \mathrm{CaCl}_{2}$, and $1 \mathrm{~mm}$ reduced glutathione $(\mathrm{pH} 7.4$ $310 \pm 5 \mathrm{mOsm}$ ). Pipette access resistance was $<3 \mathrm{M} \Omega$ and seal resistance was $>1 \mathrm{G} \Omega$.

\subsection{Statistical analysis}

Normality of the distribution of datasets was tested using the Shapiro-Wilk normality test. Non-parametric statistical methods were employed to determine the difference between groups. The Mann-Whitney $U$ test and Steel test were used for single and multiple comparisons respectively. All bargraphs indicate the mean \pm SEM unless otherwise stated.

\section{Results}

\subsection{Design and characterization of the PA-collagen hybrid matrix}

The PAs used here have a molecular design that enables the molecules to self-assemble into nanofibers that gel upon screening the amino acid charges by ionic strength or $\mathrm{pH}$ changes $[22,40]$. For the hybrid matrix preparation, we chose positively charged PAs, which are soluble at low $\mathrm{pH}$ and upon neutralization form nanofibers and gels if the concentration of PA is high enough. Collagen similarly requires an increase in $\mathrm{pH}$ to form fibrous network gels from solution, so the use of positively charged PAs allows for uniform mixing with collagen prior to gelation. In addition, the PA molecules used here have a branched molecular structure (Fig. 1A), obtained by the introduction of a lysine dendron moiety onto the peptide backbone $[35,41]$. Such a branched design has been previously shown to enhance epitope accessibility to cell receptors, and also allows simultaneous presentation of two epitopes on a single PA molecule [35,42]. To mimic laminin function, the PA molecules used were functionalized with laminin-derived bioactive peptide sequences, either IKVAV alone (IKVAV-PA) or both IKVAV and YIGSR (IKVAV/YIGSR-PA).

Although both PAs $(2 \mathrm{mg} / \mathrm{ml})$ and collagen $(1.8 \mathrm{mg} / \mathrm{ml})$ are soluble at $\mathrm{pH} 4$, we observed that upon mixing they rapidly $(<30 \mathrm{~s})$ formed a highly viscous solution. This observation was confirmed by rheological measurements of the storage modulus $\left(\mathrm{G}^{\prime}\right)$ of the mixture ( $21 \pm 5 \mathrm{~Pa}$ at $10 \mathrm{~s}^{-1}$ angular frequency), several orders of magnitude higher than that of the individual components (Fig. 1B). Moreover, the $\mathrm{G}^{\prime}$ value of the collagen-PA mixture is greater than the loss modulus $\left(G^{\prime \prime}\right)$ over the observed frequency range of $1-100 \mathrm{~s}^{-1}$, indicating the formation of weak gels (Fig. S1). To examine whether this change is driven by collagen induced assembly of the PAs, the $\beta$-sheet secondary structure (a characteristic of PA nanofibers [43]) was evaluated by circular dichroism spectroscopy (CD). Measured at $\mathrm{pH} 4.0$, the $\mathrm{CD}$ spectrum of collagen reveals a random coil structure while PA molecules show a mixture of $\alpha$-helical and $\beta$-sheet conformations (Fig. 1C). However, mixing collagen and PAs does not change the extent of $\beta$-sheet formation in the sample. This observation was further confirmed by measuring the emission of a fluorescent dye Thioflavin T (ThT) that detects the presence of $\beta$-sheet fibrils. PA solutions ( $\mathrm{pH} \mathrm{4)} \mathrm{show} \mathrm{an} \mathrm{emission}$ peak at $472 \mathrm{~nm}$ (excitation: $440 \mathrm{~nm}$ ), but addition of collagen fails to induce any change in the emission spectrum (Fig. 1D). As expected, at $\mathrm{pH} 7$ the PA solution reveals an increase in emission intensity by approximately $54 \%$, suggesting the formation of additional $\beta$-sheets due to neutralization of the PA molecules. These results suggest that collagen has minimal influence on PA selfassembly at low $\mathrm{pH}$.

To understand how the PAs and collagen interact when mixed, we performed atomic force microscopy to examine their structure (AFM). Aqueous solutions of PA molecules (sonicated in a water bath for $20 \mathrm{~min}$ in order to breakdown larger assemblies; Fig. S2) are found to form short nanofibers on the length scale of hundreds of nanometers (Fig. 2A). Since collagen does not adsorb to untreated mica [44], nanostructures are not observed in samples prepared from collagen solutions (Fig. 2B). However, in the collagen-PA mixture thin fibers of heights 1-1.5 nm, matching with the dimension of collagen triple helix molecule $(\sim 1.5 \mathrm{~nm}$ diameter), are found interspersed between PA nanofibers (height $>4 \mathrm{~nm}$ ), suggesting that collagen molecules form a complex with PA when mixed (Fig. 2C). This observation was confirmed by transmission electron microscopy (TEM). TEM micrographs of negatively stained collagen-PA samples reveal the close association of collagen triple helices ( $\sim 1.5 \mathrm{~nm}$ diameter) with PA nanofibers (diameter $\sim 9 \mathrm{~nm}$ ) (Fig. S3). In order to eliminate the possibility that this association 
A

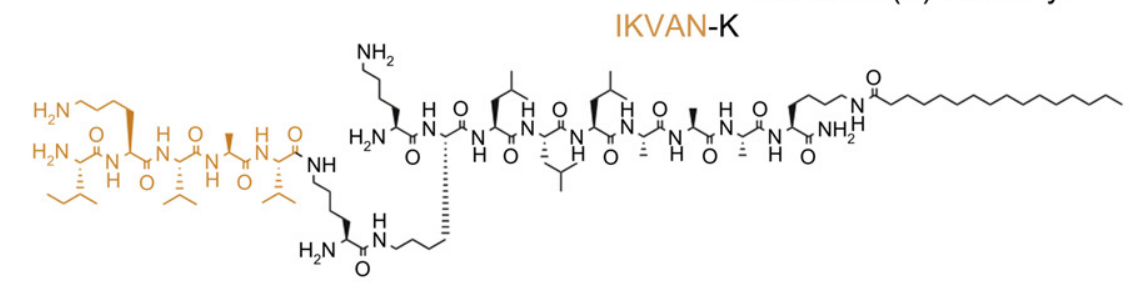
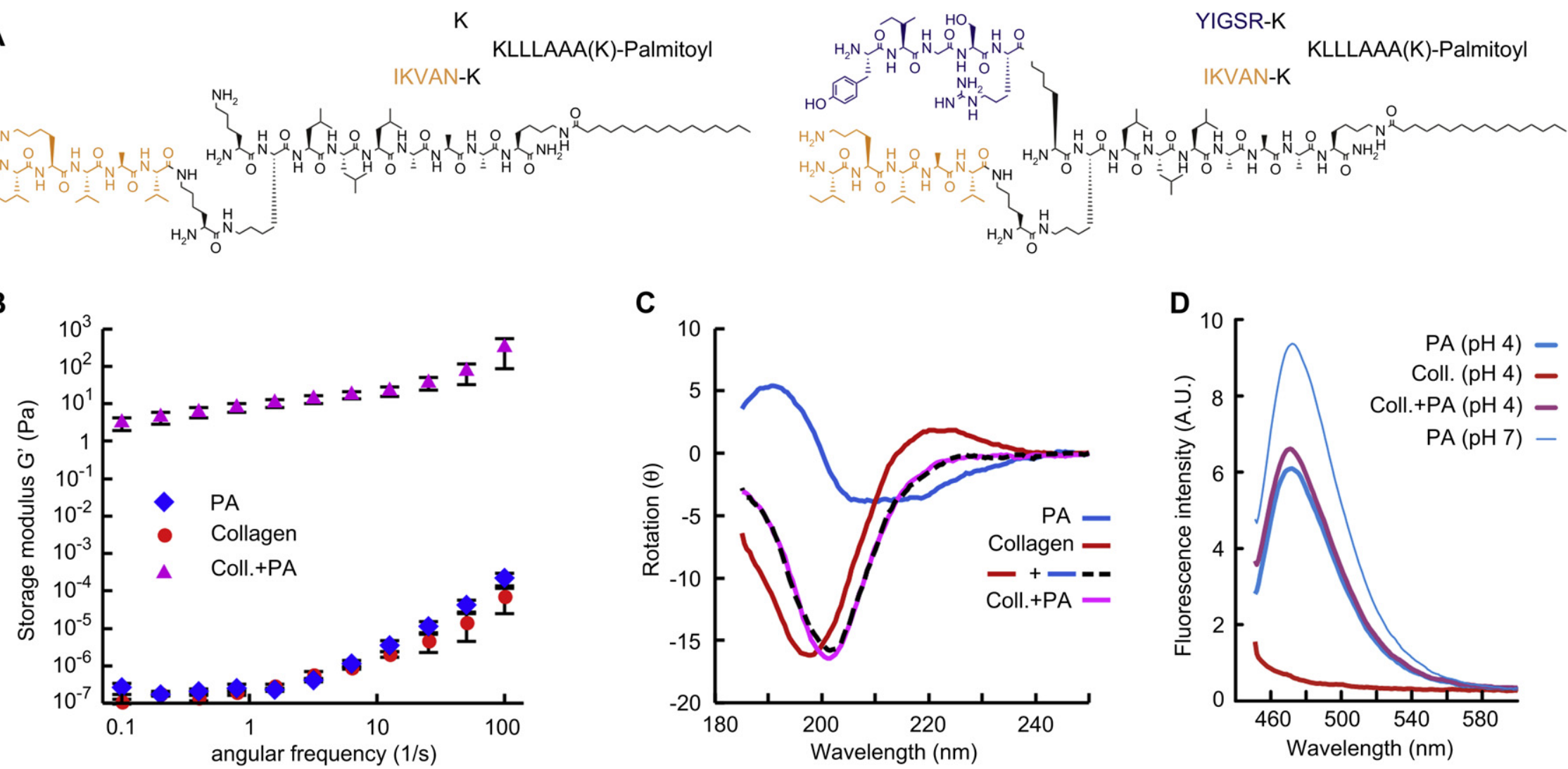

C

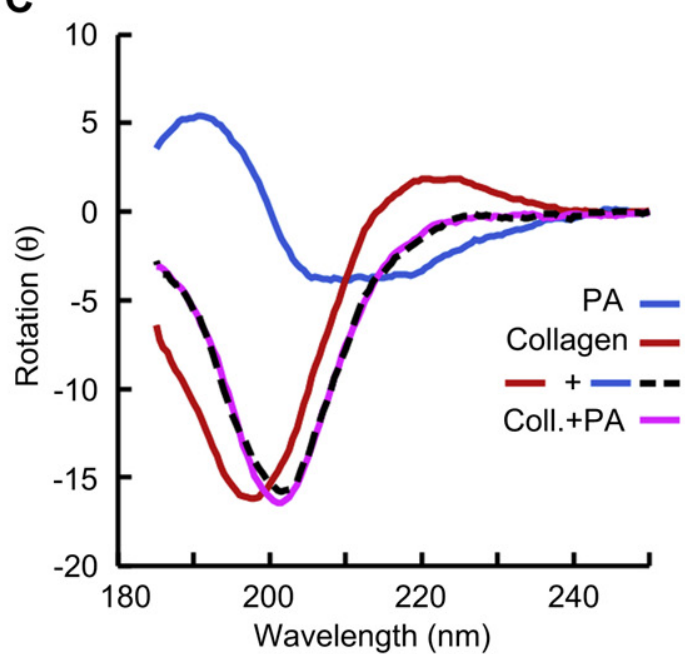

D

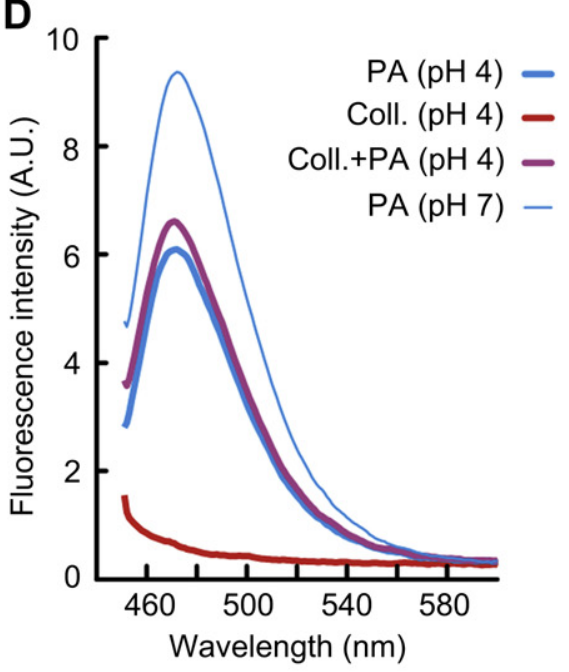

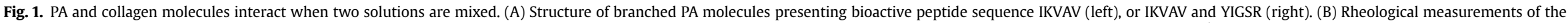
collagen solution (type I, $1.8 \mathrm{mg} / \mathrm{ml}$ ), PA solution (IKVAV/YIGSR-PA $2.0 \mathrm{mg} / \mathrm{ml}$ ) and their mixture (collagen $1.8 \mathrm{mg} / \mathrm{ml}, \mathrm{PA} 2.0 \mathrm{mg} / \mathrm{ml}$ ) over an angular frequency range of $0.1-100 \mathrm{~s}^{-1}\left(0.5 \%\right.$ strain; $5{ }^{\circ} \mathrm{C}$, pH 4 ) show a large increase in the storage modulus $\left(\mathrm{G}^{\prime}\right)$ upon mixing. (C) Circular dichroism spectra of collagen and IKVAV/YIGSR-PA solutions ( $\mathrm{pH}$ 4); linear summation of their individual spectra (black curve) overlays the signal from collagen-PA mixed solution. (D) Detection of $\beta$-sheet secondary structure by Thioflavin T (ThT) fluorescence: ThT emission spectra in presence of collagen $(1.8 \mathrm{mg} / \mathrm{ml}), \mathrm{IKVAV} / \mathrm{YIGSR}-\mathrm{PA}(2.0 \mathrm{mg} / \mathrm{ml})$ and collagen/PA mix at the indicated pH are shown $\left(\lambda_{\mathrm{ex}}=440 \mathrm{~nm}\right)$. 

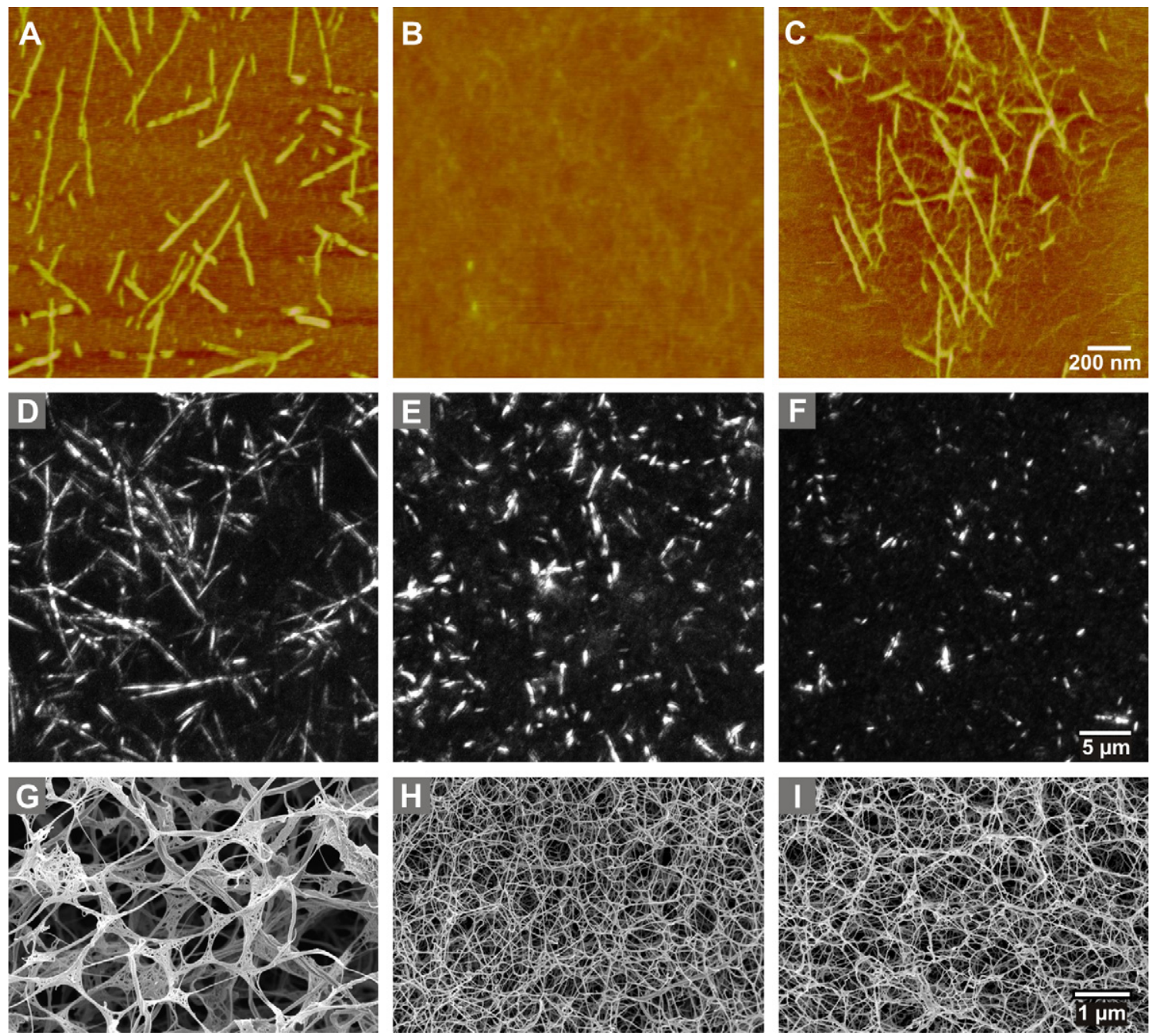

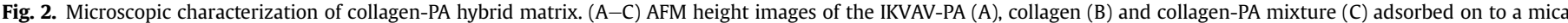

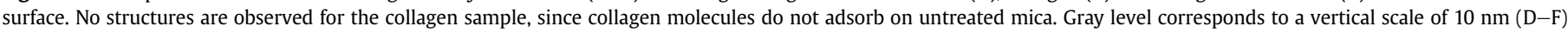

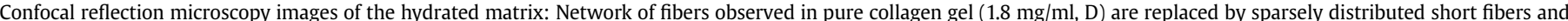

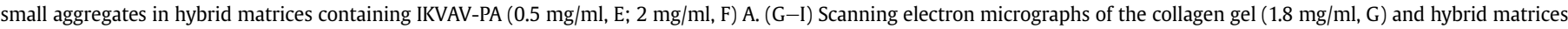
formed by addition of IKVAV/YIGSR-PA $(0.5 \mathrm{mg} / \mathrm{ml}, \mathrm{H} ; 2 \mathrm{mg} / \mathrm{ml}, \mathrm{I})$.

results from drying effects during sample preparation, we performed cryogenic-TEM, which provides structural details under hydrated conditions. Unfortunately, the contrast of collagen molecules is too low to be visualized under cryo-TEM. However, long parallel PA nanofibers (not sonicated) form a highly entangled network upon mixing with collagen, suggesting their interaction (Fig. S4). This interaction, apart from the influence on PA nanofiber association, is therefore expected to limit the free movement of collagen molecules in solution.

We next evaluated whether the collagen-PA interaction had an effect on collagen fiber assembly in gels used for cell experiments. We observed that collagen solutions $(1.8 \mathrm{mg} / \mathrm{ml})$ gelled by exposure to ammonia vapor had a comparable stiffness to the hybrid matrix containing $0.5-2.0 \mathrm{mg} / \mathrm{ml}$ of PA ( $\mathrm{G}^{\prime} 20-100 \mathrm{~Pa}$ at angular frequency of $10 \mathrm{~s}^{-1}$ ). Confocal reflection microscopy (CRM) of the hydrated collagen gel reveals network of collagen fibers (Fig. 2D), consistent with previous reports [45]. However, the presence of even relatively small amounts of PA $(0.5 \mathrm{mg} / \mathrm{ml})$ causes a noticeable reduction in fiber density and length, and at higher PA concentration (2 $\mathrm{mg} / \mathrm{ml}$ ) only small and sparsely distributed aggregates are observed (Fig. 2E,F). Nanofibers from pure PA gels $(5 \mathrm{mg} / \mathrm{ml}$, concentration at which it forms self-supporting matrices) were also not visible under CRM. Scanning electron microscopy (SEM) of the gels supports the CRM findings. Collagen fibers in pure collagen gels $(1.8 \mathrm{mg} / \mathrm{ml})$ demonstrate various degrees of bundling, resulting in fiber diameters ranging from 20 to $200 \mathrm{~nm}$ and mesh size in the order of microns (Fig. 2G). In contrast, hybrid matrices with both (low $0.5 \mathrm{mg} / \mathrm{ml}$ ) and high $(2 \mathrm{mg} / \mathrm{ml}$ ) PA content show a nearly uniform fiber diameter $(20-30 \mathrm{~nm})$ and a fine reticular structure, leading to a homogeneously smaller mesh size (Fig. 2H,I). Since the collagen content of the hybrid matrix is equal to that of pure collagen gel, these thin fibers (optically transparent to CRM) must have collagen as one of their structural components (we did not investigate further whether collagen exists as a composite with PA within these fibers or forms a distinct population separate from PA nanofiber bundles).

\subsection{Neuron attachment and survival}

To evaluate if the laminin epitopes presented on the PAs improve hybrid matrix bioactivity, we first checked their ability to promote cell attachment. Freshly dissociated cerebellar cells 
demonstrate substantially improved attachment on PA-containing substrates (Fig. 3A). On pure collagen cell attachment is poor, as revealed by the formation of cell clumps at the gel surface. The PAs, either alone $(5 \mathrm{mg} / \mathrm{ml}$ ) or as hybrids with collagen, allowed uniform adhesion of the cells, with an attachment density comparable to that observed on poly-lysine/poly-ornithine-coated glass surfaces, previously optimized for this cell suspension $[38,39]$. To exclude the possibility that the enhanced cell attachment on the hybrid matrix results from the combination of collagen with any $\beta$-sheet forming peptide sequence, we also tested the commercial product Puramatrix ${ }^{\mathrm{TM}}$ that self-assembles to form a gel but is devoid of any bioactive epitope sequence. Combination of Puramatrix with collagen failed to induce any improvement of cell attachment. These experiments thus confirm the specific role of the PAs in cell attachment on the hybrid matrix, and also suggest that the PA epitopes in the matrix are accessible to cells.

Following initial attachment, the matrix should provide specific ECM-derived signals to the developing neurons in order to promote their survival and morphogenesis. Overall neuronal survival was assessed by estimating the density of GC (positive to neuron-specific nuclear protein NeuN [46]), which represent the most numerous neuronal population of the cerebellum. Observed at 16 days in vitro (DIV), NeuN + neuronal soma as well as their neurites (visualized by tubulin $\beta$-III staining) are found to be uniformly distributed on the hybrid matrix surface while on collagen they form clumps, mirroring their initial distribution immediately after seeding (Fig. 3B). Furthermore, GC density shows a strong dependence on the PA concentration. The cell density sharply increases with the IKVAV-PA concentration in the matrix, and reaches a plateau of roughly threefold higher density than on a collagen gel at PA concentrations above $0.25 \mathrm{mg} / \mathrm{ml}$ (Fig. 3C). Therefore when evaluated in terms of GC survival, this result demonstrates the benefit of bioactive PA incorporation in the hybrid matrix.

We then evaluated the survival of PCs. Interestingly, the relationship between PA concentration and PC survival does not follow a classical saturation curve but is instead bell-shaped with an optimal PA concentration of $\sim 0.25 \mathrm{mg} / \mathrm{ml}$ and $\sim 0.5 \mathrm{mg} / \mathrm{ml}$, for the IKVAV-PA and IKVAV/YIGSR-PA, respectively (Fig. 3D,E). PC density increases by 3-5 fold at the optimal PA level. At PA concentrations above $1 \mathrm{mg} / \mathrm{ml}$ this effect reverses, with a lower cell survival compared to the pure collagen substrates. Although a substantial improvement in PC survival could be achieved by incorporating an optimal amount of laminin epitope-presenting PA in the matrix, combined presentation of IKVAV and YIGSR epitope fails to yield any additional benefit over the IKVAV epitope alone. Moreover, addition of soluble IKVAV peptide $(850 \mu \mathrm{M}$, $0.44 \mathrm{mg} / \mathrm{ml}$ ) to the culture medium does not have any significant effect on the PC density when grown on a collagen substrate ( $p>0.05$, Fig. $3 F$ ), indicating that epitope immobilization on the supramolecular scaffold formed by the PA molecules is necessary for the observed cellular response.

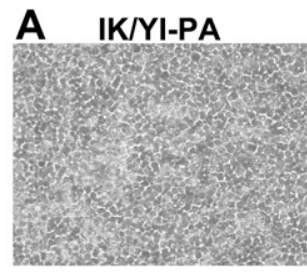

IK-PA + coll.

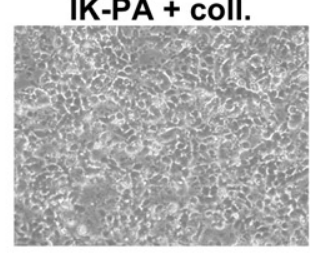

C

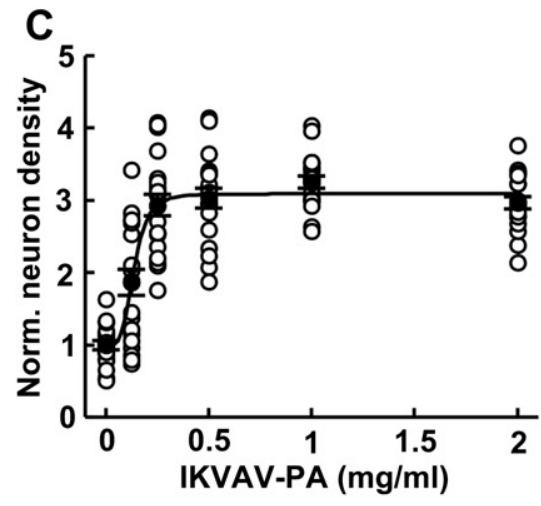

IK/YI-PA + coll.

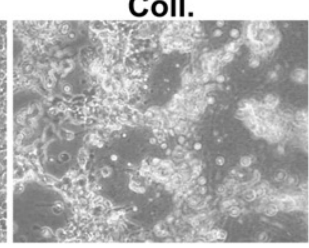

Puramatrix + coll.

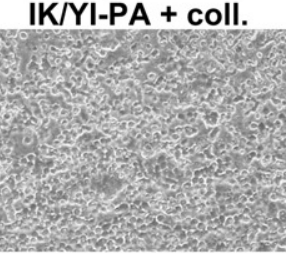

Poly-Lys coverslip
B

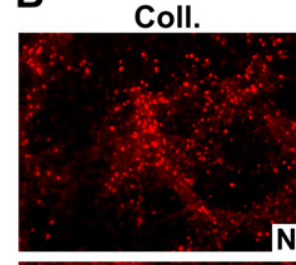

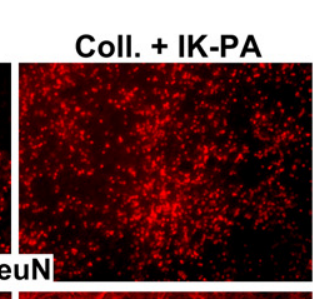

.

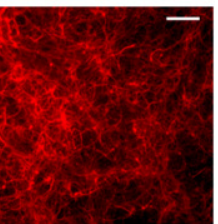

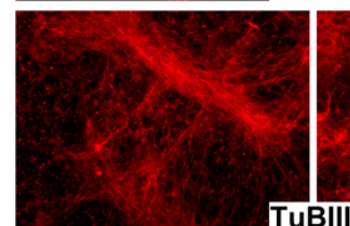

F
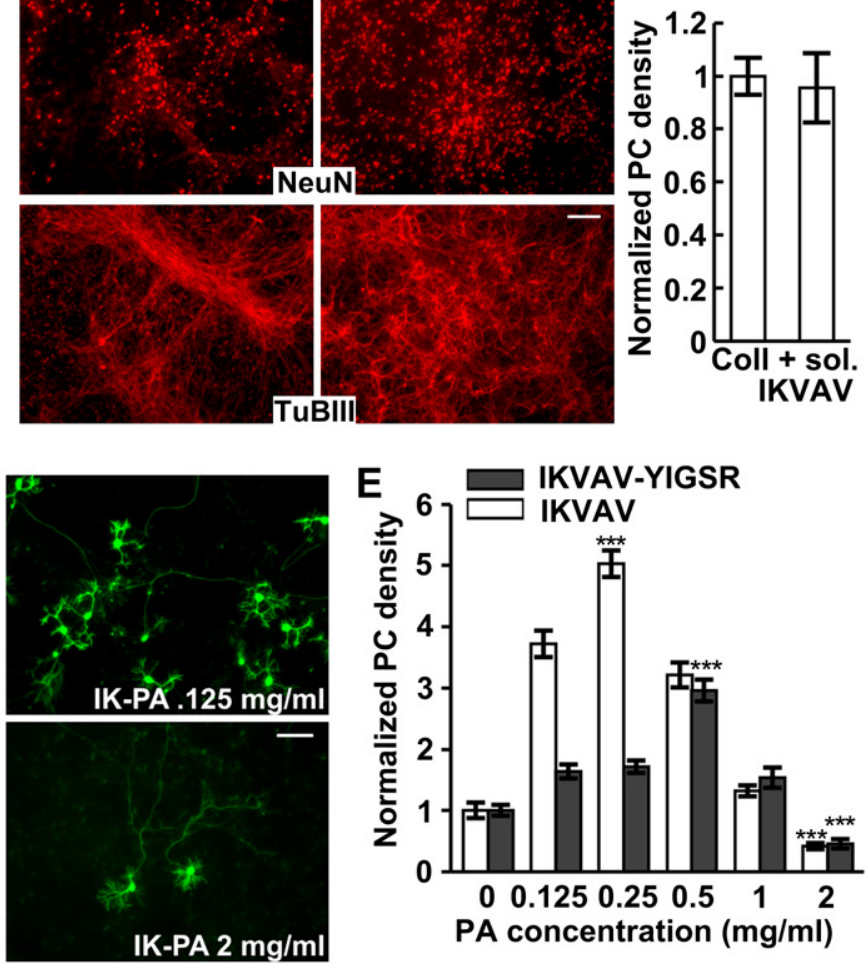

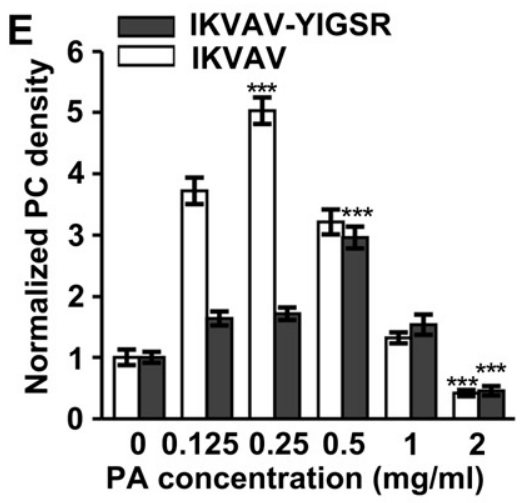

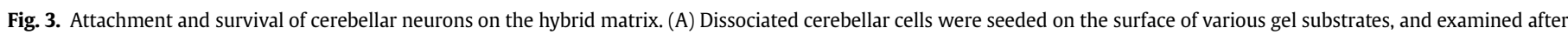

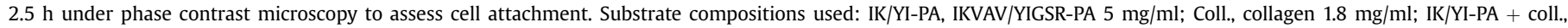

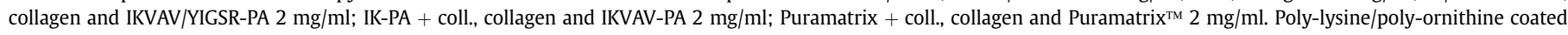

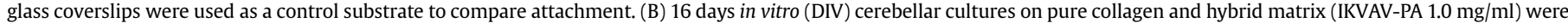

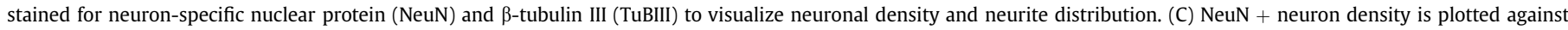

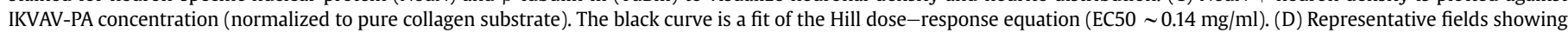

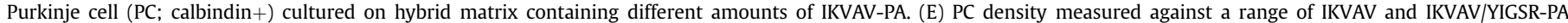

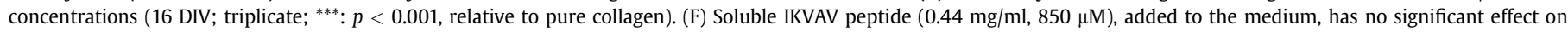
the PCs number cultured on collagen substrate. Scale bars (micron) A, 50; B and D, 100. 


\subsection{PC morphogenesis}

In addition to the effect of the hybrid supramolecular structure on survival, substrate composition is expected to influence neuronal maturation. The characteristic morphology of PC dendrites and axons allowed us to separately assess the effect of the PA on these two functionally different neuronal processes. Since cerebellar neurons were seeded on the surface of pre-formed gels in our experiments, dendrite growth was possible in two directions: (a) within the interface between gel and the culture medium ("surface dendrites"), and (b) into the hybrid gel substrates ("penetrating dendrites"). We observed that when cultured on hybrid matrix with low PA concentration $(0-0.5 \mathrm{mg} / \mathrm{ml})$, PCs and other neuronal populations extended their dendrites (MAP2+) primarily on the matrix surface, the plane of least resistance, with occasional shallow penetrations (Fig. 4A,B; movie S1). However, at higher PA concentrations $(\geq 1.0 \mathrm{mg} / \mathrm{ml})$, an extensive population of penetrating dendrites could be found in PCs (Fig. 4A, B; movie S2). These penetrating dendrites always originate from the undersurface of the PC soma, are highly branched and are thinner than surface dendrites. Apart from the difference in spatial distribution and morphology, surface and penetrating dendrites exhibit a distinct response to PA concentration in the matrix. While the IKVAV-PA promotes the growth of penetrating dendrites in a dose dependent manner (Fig. 3D), surface dendrite growth is stimulated at lower PA concentrations and is strongly inhibited when the PA concentration is high $(\geq 1 \mathrm{mg} / \mathrm{ml})$. Quantification of the surface growth by surface area and convex hull measurement (see methods) shows that the optimum IKVAV-PA concentration for maximal growth of surface dendrites is $\sim 0.25 \mathrm{mg} / \mathrm{ml}$, where the area and convex hull are $155 \pm 8 \%$ and $187 \pm 11 \%$ relative to collagen control, respectively (Fig. 4C). Branched IKVAV/YIGSR-PA produced similar effects on PC dendrite morphology (Fig. 4D). The two types of dendritic growth observed here may represent different PC response to laminin epitopes since their characteristics are retained once originated from the cell soma. Specifically, we did not observe any branches of surface dendrites entering the substrate at some distance from the soma and acquiring a penetrating dendrite morphology, neither did the penetrating dendrites resurface and transform into surface dendrites.

Supplementary video related to this article can be found at doi: 10.1016/j.biomaterials.2011.09.093

The axons of PCs also respond differentially to the presence of PA in the substrate. On collagen, the axons extend exclusively at the gel-solution interface region and show limited terminal branching (Fig. 4E). In contrast, on gels containing low concentrations of PA $(0.125 \mathrm{mg} / \mathrm{ml})$, we observed extensive terminal branching, often associated with prominent invasion of the gel substrate. This effect became much less prominent when the PA concentration was increased. Interestingly, the penetration of dendrites and axons into the substrate appears to be limited to PCs. Over the range of concentrations studied here, other neuronal populations present in the culture rarely extend their neurites into the substrate (Fig. 4A).

\subsection{Development of synaptic connectivity}

To assess whether the neurons cultured on the hybrid matrix integrate into a functional network, we examined synaptic connectivity and synaptically evoked electrical activity in PC neurons. We observed that PC surface dendrites in mature culture
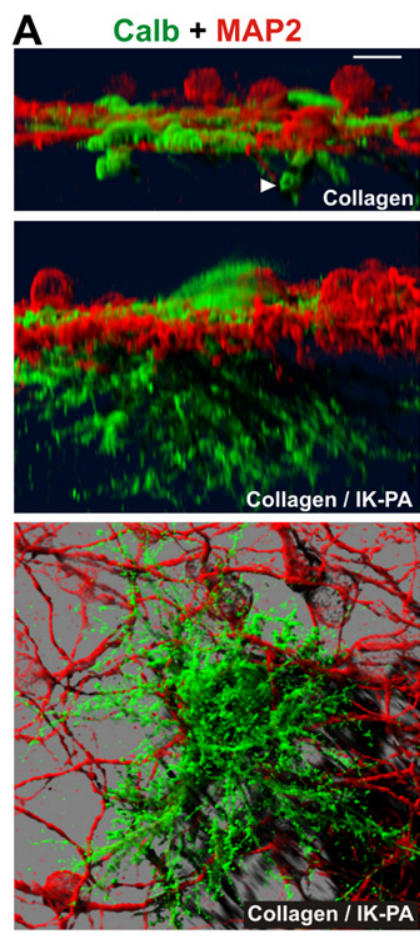

B
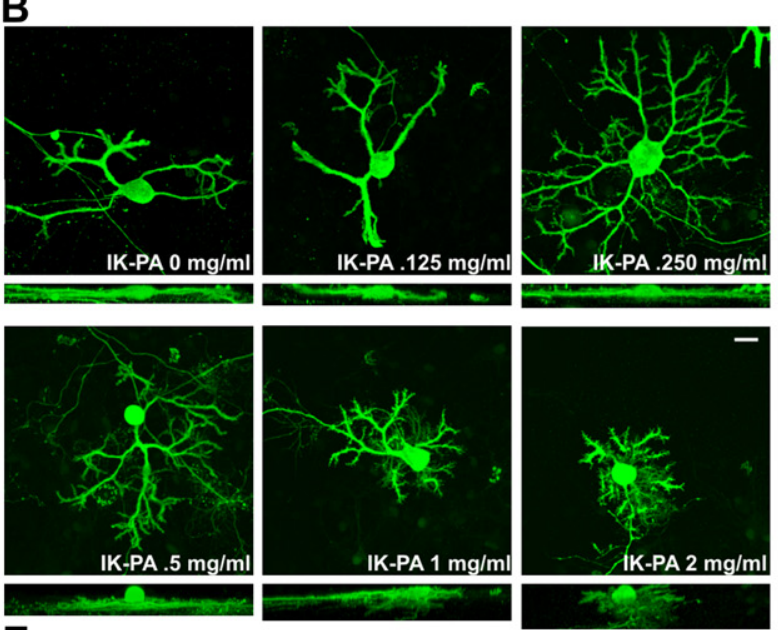

E
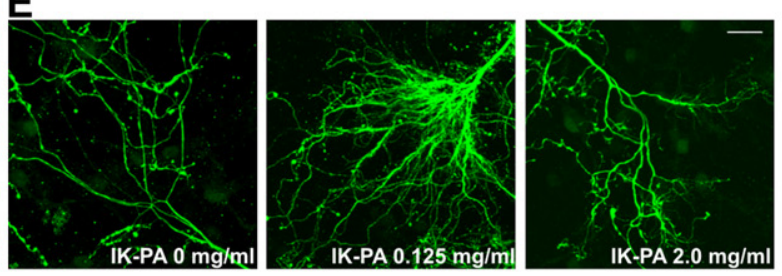

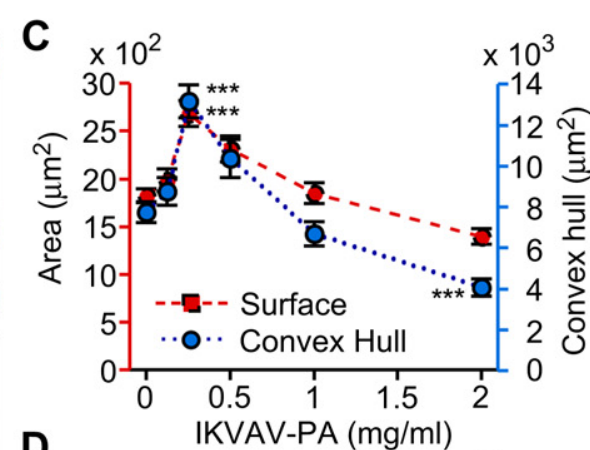

D

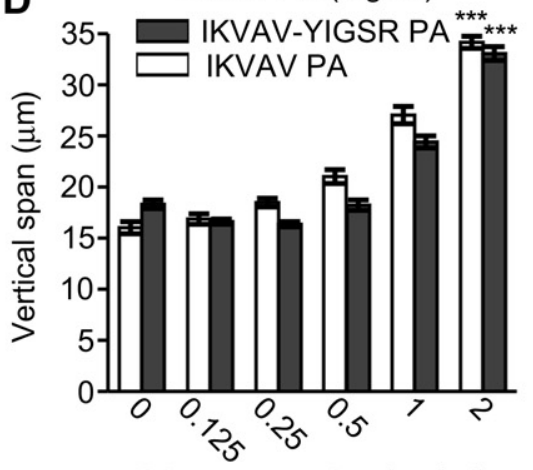

PA concentration $(\mathrm{mg} / \mathrm{ml})$

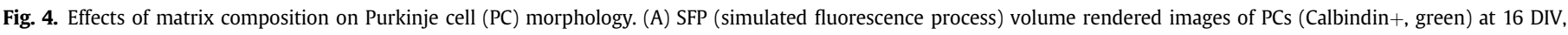

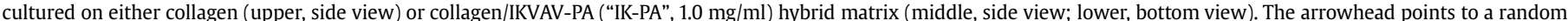

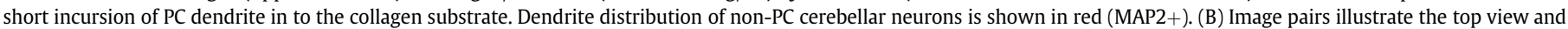

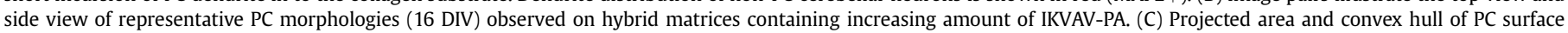

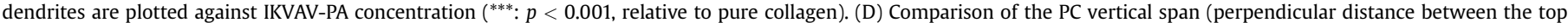

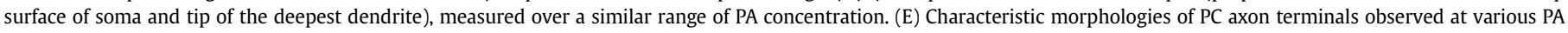
concentrations. Scale bars (micron) A, 10; B and E, 20. 
receive a high density of synaptophysin-containing axon terminals on their spines, mirroring normal synaptic contacts in vivo (Fig. 5A, B). The presence of PA appears to increase spine density along dendrites when compared to collagen, although this parameter has not been quantified here. To examine if these physical connections are functionally active, we recorded electrical activity from PCs; in all recorded PCs $(n=7)$ we detected spontaneous excitatory postsynaptic currents (Fig. 5C), indicative of active synaptic transmission. In addition, the excitability of the PCs and their ability to generate sodium and calcium action potentials were demonstrated by injection of depolarizing current into PCs, triggering discharge of both slow and fast action potentials characteristic of this neuronal type.

\section{Discussion}

We have described here a bioactive supramolecular matrix that supports the survival and normal functions of neurons from the central nervous system. This matrix integrates the mechanical functions of collagen with that of highly bioactive nanofibers displaying laminin epitopes. This design allowed adjustment of the laminin epitope density within the matrix over an order of magnitude, without compromising its structural integrity. We have further demonstrated that a functional neuronal network can be constructed on this hybrid scaffold system, and neuronal survival and morphology can be controlled by tuning the laminin epitope density (Fig. 6B).
The integration of collagen and a laminin mimic supramolecular system to produce a hybrid matrix has allowed us to optimize both the mechanical properties and bioactivity. Interestingly, previous attempts to combine the functions of collagen and laminins in a scaffold matrix using either native laminin protein or laminin rich matrigel only led to a limited improvement of scaffold bioactivity [47-49]. The major limitation of this approach has been linked to an inhomogeneous distribution of laminin aggregates within the collagen matrix, and a consequent deterioration of matrix mechanical properties [50]. The formation of collagen fibers from a solution of triple helical collagen molecules involves assembly in both the longitudinal and lateral directions, with the formation of intermediary microfibril structures [51,52] (Fig. 6A). In the supramolecular hybrid matrix studied here, we hypothesize that PA cylindrical aggregates, known to be highly hydrated [53], become embedded in the collagen fiber bundles with nanoscale dispersion. Our proposed model is based on the observation that collagen molecules interact with PA nanofiber assemblies at low $\mathrm{pH}$, but transform at physiological $\mathrm{pH}$ into surprisingly monodisperse fibers, not observed in pure collagen matrix. This implies that both collagen and the PA assemblies are closely associated in the network fibers of fairly uniform diameter, and a plausible model involves collagen molecules displacing the hydration shell in PA assemblies. This arrangement would be entropically favored as water molecules bound to PA molecules in their cylindrical aggregates would be liberated and the volume replaced by collagen. We also propose that the uniform diameter of the hybrid fibers,
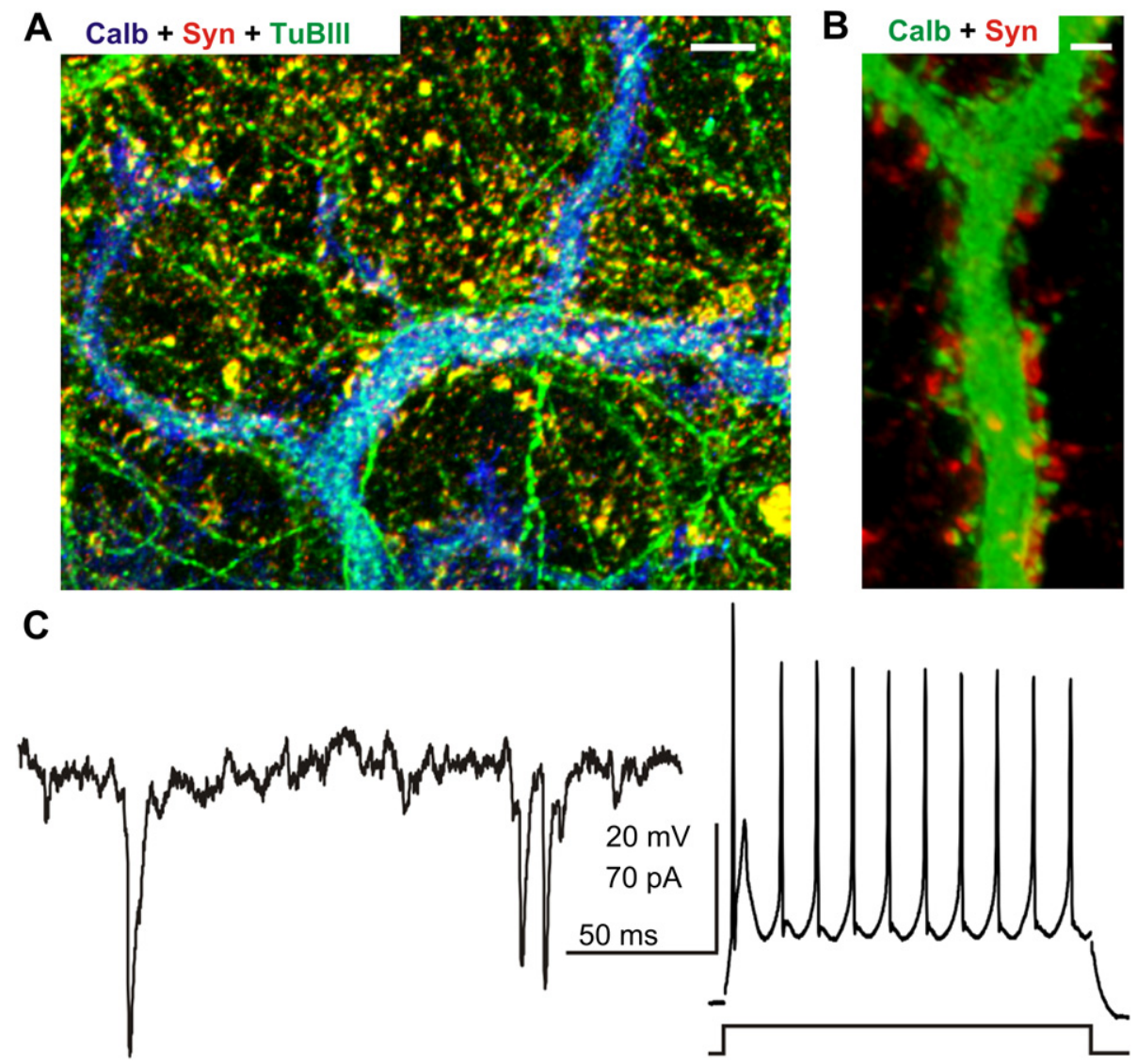

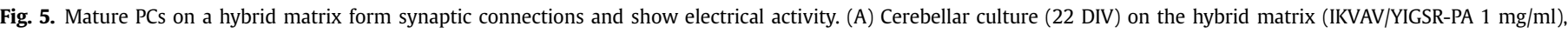

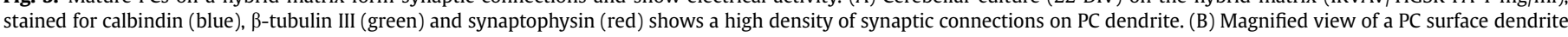

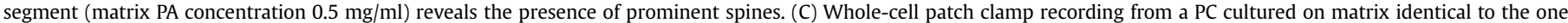

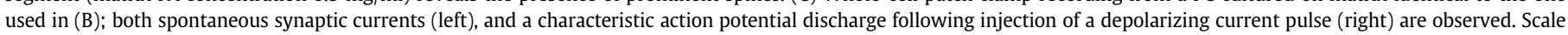
bars (micron) A, 5; B, 2. 

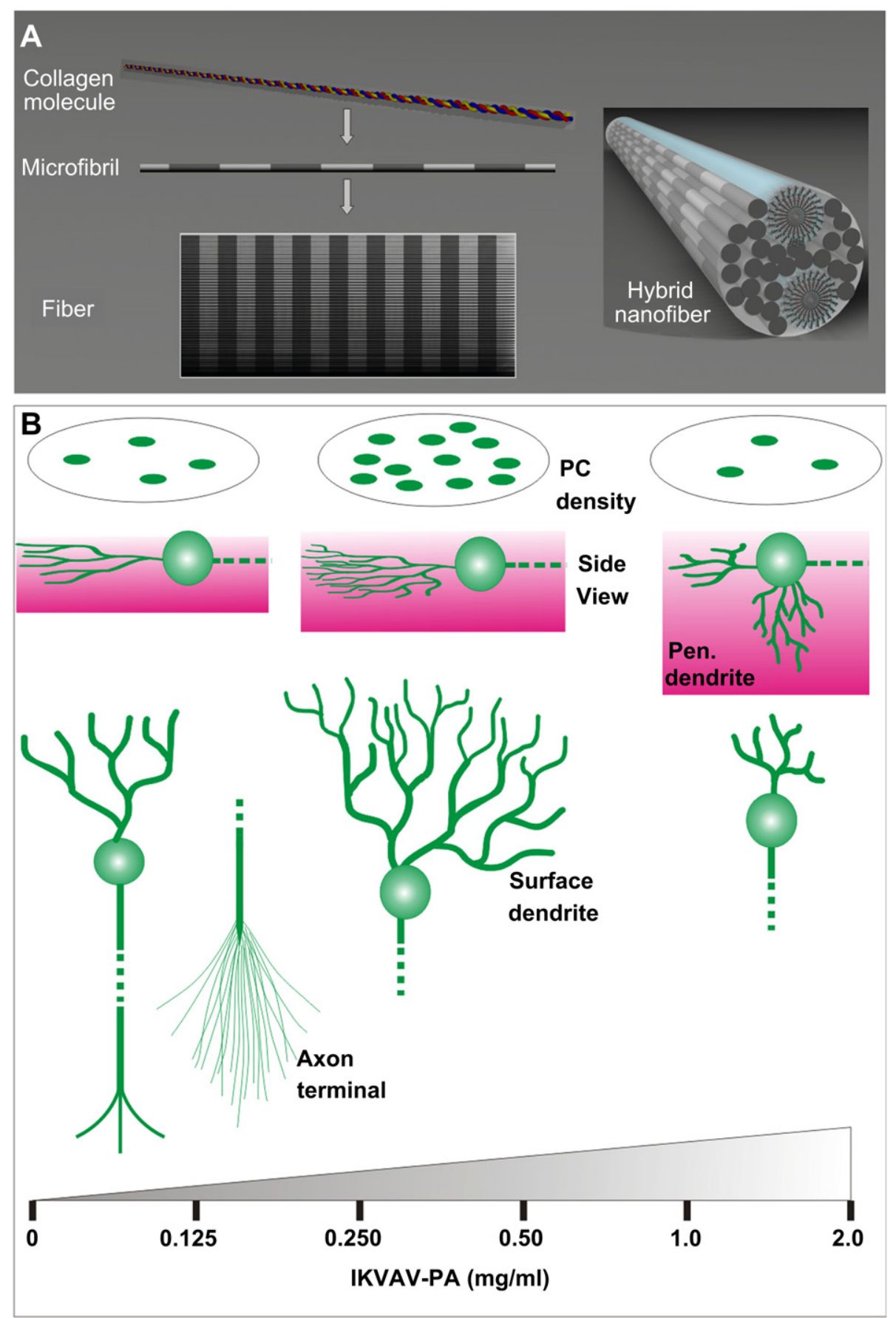

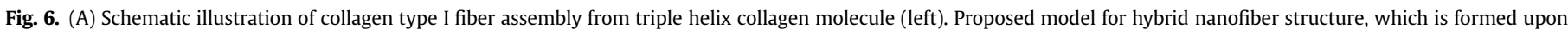
co-assembly of PA and collagen molecules (right; image not to scale). (B) Summary of PC response to hybrid matrix at various IKVAV-PA concentrations.

exceeding that of PA nanofibers, is rooted in a nucleation event that offers an optimal structure containing the supramolecular aggregates embedded in a collagen matrix. Given the aqueous environment in which these hybrid structures form, the surface of the fibers must have exposed PA assemblies explaining the bioactivity we observed. Modification of the collagen scaffold by covalent grafting of YIGSR laminin epitope sequence has been previously shown to promote neurite outgrowth in vitro [54] and axonal regeneration in vivo [21]. Presentation of the laminin epitopes in the matrix through the supramolecular assemblies of PA molecules offers the advantage of tight control upon epitope density without the need for complex chemical reactions to couple the peptide to the matrix.

We have demonstrated here that PCs cultured on a hybrid matrix substrate have two distinct forms of dendrite growth. The surface dendrites are morphologically similar to the dendrites found on 2D substrates or on pure collagen gels; they exhibit an adhesive epitope density dependent biphasic response [55] with the maximal growth observed at moderate laminin epitope concentration (IKVAV-PA $0.25 \mathrm{mg} / \mathrm{ml}$ ). In contrast, penetrating dendrites develop better in a PA-rich matrix $(\geq 1 \mathrm{mg} / \mathrm{ml})$, and are absent in collagen gels even having a comparable stiffness and 
a much larger mesh size, indicating that the high level of laminin epitope concentration offered by the supramolecular systems exert an attractive guiding force toward growing dendrites. Thus, our results suggest that laminin has at least two different modes of influencing PC dendrite growth. In addition to dendrites, axon morphology shows a substantial dependence on laminin epitope density, with maximum terminal branching observed at an IKVAVPA concentration of $0.125 \mathrm{mg} / \mathrm{ml}$, lower than the optimum concentration for surface dendrite growth. Therefore, even though the growth of dendrites and axons are often broadly considered under the category of "neurite growth", our results underline a very different matrix requirement for their optimal development.

The possibility of controlling the density of laminin epitopes in a mechanically stable hybrid matrix revealed a differential response of morphological attributes from the same neuron. However, we also observed that different neuronal populations from the same brain region exhibit a distinct response to the laminin epitope concentration in the surrounding matrix. While GC survival is maximized at PA concentrations above $0.25 \mathrm{mg} / \mathrm{ml}$, for PCs this concentration is optimal and survival rate was found to decrease at higher PA concentrations. Dendritic penetration into the matrix was observed for PCs at higher PA concentrations, but was never found in GCs over the entire range of PA concentration tested. This variability can be explained by a difference in their expression of integrin/non-integrin ECM receptors to which the laminin epitopes bind [56]. The neuron-specific response to the laminin epitopes could also explain why the IKVAV/YIGSR combination had no additional advantage over IKVAV on cerebellar neurons, even though the combination was previously shown to produce synergistic beneficial effects on the neurite growth of pyramidal neurons [57] and non-additive effects on dorsal root ganglion neurons [18]. Since neuronal development takes place in a strictly sequential manner in the developing cerebellum [58] accompanied by a fast spatial redistribution of laminin [59], we assume that the differential effects observed here reflect their in vivo response to laminin. From a substrate engineering point of view, these observations underline the fact that the matrix composition needs to be carefully tailored to match the requirements of specific sub-regions of the brain, and the tunable epitope concentration afforded by self-assembling supramolecular systems provide a useful way to achieve control over the development of a targeted neuron population.

\section{Conclusions}

We have demonstrated that synthetic hybrid matrices formed by co-assembly of ECM biopolymers and self-assembling bioactive molecules can be molecularly tuned to support neuronal survival and morphogenesis. The hybrid matrix approach, with its easily adjusted epitope densities, offers the possibility of studying in vitro the complex interaction of specific extracellular signals, their concentration, and the matrix mechanical properties on the responses of brain neurons. The matrix investigated here and similar systems can also be translated to biodegradable and bioactive scaffolds for nerve tissue regeneration.

\section{Acknowledgments}

This work was funded by the National Institutes of Health (NIH)/ NIBIB Award No. 5R01EB003806-04 and RIKEN BSI intramural funding. AFM imaging was conducted at the Northwestern Nanoscale Integrated Fabrication, Testing, and Instrumentation Facility (NIFTI), TEM was conducted at the Northwestern Cell Imaging Facility, and cryogenic TEM was conducted at the Northwestern Biological Imaging Facility (BIF). SEM was performed by the
Support Unit for Biomaterials Analysis in RIKEN BSI Research Ressources Center. The authors gratefully acknowledge the technical assistance provided by Yumiko Motoyama, Krista Niece, Megan Greenfield, Reiko Nakatomi and Christina Newcomb for cell culture, PA synthesis, rheology, SEM and TEM respectively.

\section{Appendix. Supplementary material}

Supplementary material associated with this article can be found, in the online version, at doi:10.1016/j.biomaterials.2011. 09.093.

\section{References}

[1] Schmidt CE, Leach JB. Neural tissue engineering: strategies for repair and regeneration. Annu Rev Biomed Eng 2003;5:293-347.

[2] Haas S, Weidner N, Winkler J. Adult stem cell therapy in stroke. Curr Opin Neurol 2005;18:59-64.

[3] Silva GA, Czeisler C, Niece KL, Beniash E, Harrington DA, Kessler JA, et al. Selective differentiation of neural progenitor cells by high-epitope density nanofibers. Science 2004;303:1352-5.

[4] Lavik EB, Klassen $H$, Warfvinge $K$, Langer R, Young MJ. Fabrication of degradable polymer scaffolds to direct the integration and differentiation of retinal progenitors. Biomaterials 2005;26:3187-96.

[5] Orive G, Anitua E, Pedraz JL, Emerich DF. Biomaterials for promoting brain protection, repair and regeneration. Nat Rev Neurosci 2009;10:682-92.

[6] Lutolf MP, Hubbell JA. Synthetic biomaterials as instructive extracellular microenvironments for morphogenesis in tissue engineering. Nat Biotechnol 2005;23:47-55.

[7] Dvir T, Timko BP, Kohane DS, Langer R. Nanotechnological strategies for engineering complex tissues. Nat Nanotechnol 2011;6:13-22.

[8] Hartgerink JD, Beniash E, Stupp SI. Self-assembly and mineralization of peptide-amphiphile nanofibers. Science 2001;294:1684-8.

[9] Cui H, Webber MJ, Stupp SI. Self-assembly of peptide amphiphiles: from molecules to nanostructures to biomaterials. Biopolymers 2010;94:1-18.

[10] Tsang KY, Cheung MC, Chan D, Cheah KS. The developmental roles of the extracellular matrix: beyond structure to regulation. Cell Tissue Res 2010;339: 93-110.

[11] Ruoslahti E. RGD and other recognition sequences for integrins. Annu Rev Cell Dev Biol 1996;12:697-715.

[12] Shin H, Jo S, Mikos AG. Biomimetic materials for tissue engineering. Biomaterials 2003;24:4353-64.

[13] Colognato $\mathrm{H}$, ffrench-Constant C, Feltri ML. Human diseases reveal novel roles for neural laminins. Trends Neurosci 2005;28:480-6.

[14] Tashiro K, Sephel GC, Weeks B, Sasaki M, Martin GR, Kleinman HK, et al. A synthetic peptide containing the IKVAV sequence from the A chain of laminin mediates cell attachment, migration, and neurite outgrowth. J Biol Chem 1989;264:16174-82.

[15] Graf J, Iwamoto Y, Sasaki M, Martin GR, Kleinman HK, Robey FA, et al. Identification of an amino acid sequence in laminin mediating cell attachment, chemotaxis, and receptor binding. Cell 1987;48:989-96.

[16] Liesi P, Narvanen A, Soos J, Sariola H, Snounou G. Identification of a neurite outgrowth-promoting domain of laminin using synthetic peptides. FEBS Lett 1989;244:141-8.

[17] Adams DN, Kao EY, Hypolite CL, Distefano MD, Hu WS, Letourneau PC. Growth cones turn and migrate up an immobilized gradient of the laminin IKVAV peptide. J Neurobiol 2005;62:134-47.

[18] Schense JC, Bloch J, Aebischer P, Hubbell JA. Enzymatic incorporation of bioactive peptides into fibrin matrices enhances neurite extension. Nat Biotechnol 2000;18:415-9.

[19] Yu TT, Shoichet MS. Guided cell adhesion and outgrowth in peptide-modified channels for neural tissue engineering. Biomaterials 2005;26:1507-14.

[20] Tysseling-Mattiace VM, Sahni V, Niece KL, Birch D, Czeisler C, Fehlings MG, et al. Self-Assembling nanofibers inhibit glial scar formation and promote axon elongation after spinal cord injury. J Neurosci 2008;28:3814-23.

[21] Itoh S, Takakuda K, Samejima H, Ohta T, Shinomiya K, Ichinose S. Synthetic collagen fibers coated with a synthetic peptide containing the YIGSR sequence of laminin to promote peripheral nerve regeneration in vivo. J Mater Sci Mater Med 1999;10:129-34.

[22] Hartgerink JD, Beniash E, Stupp SI. Peptide-amphiphile nanofibers: a versatile scaffold for the preparation of self-assembling materials. Proc Natl Acad Sci U S A 2002;99:5133-8.

[23] Rajangam K, Behanna HA, Hui MJ, Han X, Hulvat JF, Lomasney JW, et al. Heparin binding nanostructures to promote growth of blood vessels. Nano Lett 2006;6:2086-90.

[24] Shah RN, Shah NA, Del Rosario Lim MM, Hsieh C, Nuber G, Stupp SI. Supramolecular design of self-assembling nanofibers for cartilage regeneration. Proc Natl Acad Sci U S A 2010;107:3293-8.

[25] Mata A, Geng Y, Henrikson KJ, Aparicio C, Stock SR, Satcher RL, et al. Bone regeneration mediated by biomimetic mineralization of a nanofiber matrix. Biomaterials 2010;31:6004-12. 
[26] Webber MJ, Kessler JA, Stupp SI. Emerging peptide nanomedicine to regenerate tissues and organs. J Intern Med 2010;267:71-88.

[27] Velichko YS, Stupp SI, de la Cruz MO. Molecular simulation study of peptide amphiphile self-assembly. J Phys Chem B 2008;112:2326-34.

[28] Webber MJ, Tongers J, Renault MA, Roncalli JG, Losordo DW, Stupp SI. Development of bioactive peptide amphiphiles for therapeutic cell delivery. Acta Biomater 2010;6:3-11.

[29] Tysseling VM, Sahni V, Pashuck ET, Birch D, Hebert A, Czeisler C, et al. Selfassembling peptide amphiphile promotes plasticity of serotonergic fibers following spinal cord injury. J Neurosci Res 2010;88:3161-70.

[30] Kleinman HK, Klebe RJ, Martin GR. Role of collagenous matrices in the adhesion and growth of cells. J Cell Biol 1981;88:473-85.

[31] Ma W, Fitzgerald W, Liu QY, O'Shaughnessy TJ, Maric D, Lin HJ, et al. CNS stem and progenitor cell differentiation into functional neuronal circuits in threedimensional collagen gels. Exp Neurol 2004;190:276-88.

[32] Herrup K, Sunter K. Numerical matching during cerebellar development: quantitative analysis of granule cell death in staggerer mouse chimeras. J Neurosci 1987;7:829-36.

[33] Zanjani HS, Vogel MW, Delhaye-Bouchaud N, Martinou JC, Mariani J. Increased cerebellar Purkinje cell numbers in mice overexpressing a human bcl-2 transgene. J Comp Neurol 1996;374:332-41.

[34] Ito M. Cerebellar long-term depression: characterization, signal transduction, and functional roles. Physiol Rev 2001:81:1143-95.

[35] Guler MO, Hsu L, Soukasene S, Harrington DA, Hulvat JF, Stupp SI. Presentation of RGDS epitopes on self-assembled nanofibers of branched peptide amphiphiles. Biomacromolecules 2006;7:1855-63.

[36] Chandrakasan G, Torchia DA, Piez KA. Preparation of intact monomeric collagen from rat tail tendon and skin and the structure of the nonhelical ends in solution. J Biol Chem 1976;251:6062-7.

[37] Inoue T, Osatake H. A new drying method of biological specimens for scanning electron microscopy: the t-butyl alcohol freeze-drying method. Arch Histol Cytol 1988;51:53-9.

[38] Furuya S, Makino A, Hirabayashi Y. An improved method for culturing cerebellar Purkinje cells with differentiated dendrites under a mixed monolayer setting. Brain Res Brain Res Protoc 1998;3:192-8.

[39] Launey T, Endo S, Sakai R, Harano J, Ito M. Protein phosphatase 2A inhibition induces cerebellar long-term depression and declustering of synaptic AMPA receptor. Proc Natl Acad Sci U S A 2004;101:676-81.

[40] Beniash E, Hartgerink JD, Storrie H, Stendahl JC, Stupp SI. Self-assembling peptide amphiphile nanofiber matrices for cell entrapment. Acta Biomater 2005;1:387-97.

[41] Harrington DA, Cheng EY, Guler MO, Lee LK, Donovan JL, Claussen RC, et al. Branched peptide-amphiphiles as self-assembling coatings for tissue engineering scaffolds. J Biomed Mater Res A 2006;78:157-67.

[42] Storrie H, Guler MO, Abu-Amara SN, Volberg T, Rao M, Geiger B, et al. Supramolecular crafting of cell adhesion. Biomaterials 2007;28:4608-18.
[43] Behanna HA, Donners JJ, Gordon AC, Stupp SI. Coassembly of amphiphiles with opposite peptide polarities into nanofibers. J Am Chem Soc 2005;127: 1193-200.

[44] Chen Q Xu S, Li R, Liang X, Liu H. Network structure of collagen layers absorbed on LB film. J Colloid Interface Sci 2007;316:1-9.

[45] Brightman AO, Rajwa BP, Sturgis JE, McCallister ME, Robinson JP, VoytikHarbin SL. Time-lapse confocal reflection microscopy of collagen fibrillogenesis and extracellular matrix assembly in vitro. Biopolymers 2000;54:222-34.

[46] Weyer A, Schilling K. Developmental and cell type-specific expression of the neuronal marker NeuN in the murine cerebellum. J Neurosci Res 2003;73: 400-9.

[47] Battista S, Guarnieri D, Borselli C, Zeppetelli S, Borzacchiello A, Mayol L, et al. The effect of matrix composition of 3D constructs on embryonic stem cell differentiation. Biomaterials 2005;26:6194-207.

[48] Dewitt DG, Kaszuba SN, Thompson DM, Stegemann JP. Collagen I-Matrigel scaffolds for enhanced Schwann cell survival and control of 3D cell morphology. Tissue Eng Part A; 2009.

[49] Jurga M, Dainiak MB, Sarnowska A, Jablonska A, Tripathi A, Plieva FM, et al. The performance of laminin-containing cryogel scaffolds in neural tissue regeneration. Biomaterials 2011;32:3423-34.

[50] Guarnieri D,S, Battista S, Borzacchiello A, Mayol L, De Rosa E, Keene DR, et al. Effects of fibronectin and laminin on structural, mechanical and transport properties of 3D collageneous network. J Mater Sci Mater Med 2007;18:245-53.

[51] Kadler KE, Holmes DF, Trotter JA, Chapman JA. Collagen fibril formation. Biochem J 1996;316(Pt. 1):1-11.

[52] Cisneros DA, Hung C, Franz CM, Muller DJ. Observing growth steps of collagen self-assembly by time-lapse high-resolution atomic force microscopy. J Struct Biol 2006;154:232-45.

[53] Tovar JD, Claussen RC, Stupp SI. Probing the interior of peptide amphiphile supramolecular aggregates. J Am Chem Soc 2005;127:7337-45.

[54] Duan X, McLaughlin C, Griffith M, Sheardown H. Biofunctionalization of collagen for improved biological response: scaffolds for corneal tissue engineering. Biomaterials 2007;28:78-88.

[55] Schense JC, Hubbell JA. Three-dimensional migration of neurites is mediated by adhesion site density and affinity. J Biol Chem 2000;275:6813-8.

[56] Humphries MJ. The molecular basis and specificity of integrin-ligand interactions. J Cell Sci 1990;97(Pt. 4):585-92.

[57] Tong YW, Shoichet MS. Enhancing the neuronal interaction on fluoropolymer surfaces with mixed peptides or spacer group linkers. Biomaterials 2001;22: 1029-34.

[58] Sotelo C. Cellular and genetic regulation of the development of the cerebellar system. Prog Neurobiol 2004;72:295-339.

[59] Powell SK, Williams CC, Nomizu M, Yamada Y, Kleinman HK. Laminin-like proteins are differentially regulated during cerebellar development and stimulate granule cell neurite outgrowth in vitro. J Neurosci Res 1998;54: 233-47. 